\title{
Live-Load Testing Application Using a Wireless Sensor System and Finite-Element Model Analysis of an Integral Abutment Concrete Girder Bridge
}

\author{
Robert W. Fausett, Paul J. Barr, and Marvin W. Halling \\ Department of Civil and Environmental Engineering, Utah State University, 4110 Old Main Hill, Logan, UT 84322, USA \\ Correspondence should be addressed to Paul J. Barr; paul.barr@usu.edu
}

Received 3 July 2014; Revised 15 September 2014; Accepted 3 October 2014; Published 23 October 2014

Academic Editor: Eugenio Martinelli

Copyright (C) 2014 Robert W. Fausett et al. This is an open access article distributed under the Creative Commons Attribution License, which permits unrestricted use, distribution, and reproduction in any medium, provided the original work is properly cited.

\begin{abstract}
As part of an investigation on the performance of integral abutment bridges, a single-span, integral abutment, prestressed concrete girder bridge near Perry, Utah was instrumented for live-load testing. The live-load test included driving trucks at $2.24 \mathrm{~m} / \mathrm{s}$ ( $5 \mathrm{mph}$ ) along predetermined load paths and measuring the corresponding strain and deflection. The measured data was used to validate a finite-element model (FEM) of the bridge. The model showed that the integral abutments were behaving as $94 \%$ of a fixed-fixed support. Live-load distribution factors were obtained using this validated model and compared to those calculated in accordance to recommended procedures provided in the AASHTO LRFD Bridge Design Specifications (2010). The results indicated that if the bridge was considered simply supported, the AASHTO LRFD Specification distribution factors were conservative (in comparison to the FEM results). These conservative distribution factors, along with the initial simply supported design assumption resulted in a very conservative bridge design. In addition, a parametric study was conducted by modifying various bridge properties of the validated bridge model, one at a time, in order to investigate the influence that individual changes in span length, deck thickness, edge distance, skew, and fixity had on live-load distribution. The results showed that the bridge properties with the largest influence on bridge live-load distribution were fixity, skew, and changes in edge distance.
\end{abstract}

\section{Introduction}

The concept of integral abutment bridges has been implemented since 1938 when the Teens Run Bridge was constructed near Eureka, Ohio [1]. Integral abutment bridges are constructed without movable transverse deck joints at the piers or abutments and can be designed and constructed as either single or multispan bridges. The elimination of the deck joints is appealing to bridge owners due to their costly maintenance. However, this design philosophy subjects the superstructure and abutment to secondary stresses due to the continuity of the bridge from bridge settlement, backfill, and changes in temperature. Although these stresses are not ideal, the maintenance cost developed by utilizing movable deck joints is much more significant than the design requirements and construction cost developed from the secondary stresses of the integral abutments [1]. Paraschos and Made [2] provide the results of a survey of the status, problems, and cost that states have experienced using integral abutment bridges. As a result of these benefits, more and more Departments of Transportation (DOTs) are constructing bridges using integral abutment design principles. However, due to the uncertainty of the degree-of-fixity of the integral abutment, engineers typically conservatively design for bending according to simply supported assumptions.

Finite-element analysis has been a practical tool utilized in many studies of integral abutment bridges. The developed model provides an accurate representation of the in situ bridge which can then be evaluated in detail using different load locations and bridge characteristics to quantify the bridge response. In previous studies, finite-element models have been created either as a replication of an actual bridge or as a representation of a general bridge type (i.e., integral abutment and box girder). In all of these studies, simulated loads 
were applied to the finite-element models that were similar to the vehicle traffic on the bridge and the overall performance of the bridge, as well as the distribution factors, load ratings, stress, fatigue, and thermal effects, was quantified. Examples of these studies include Jáuregui and Barr [3], Mourad and Tabsh [4], Dicleli and Erhan [5], Hodson et al. [6], Lahovich [7], Cai et al. [8], Kalayc1 et al. [9], and Kim et al. [10]. Other studies involving the determination of distribution factors for other types of bridges include Ebeido and Kennedy [11], Ryan and Hindi [12], and Song et al. [13].

The finite element and integral abutment bridge studies have been conducted with and without using validated models with live-load data. Live-load distribution factors (LLDFs) have been calculated for integral abutment bridges using theoretical bridge models, such as a study conducted by Dicleli and Erhan [5], which investigated the accuracy of live-load distribution formulas for single-span, prestressed concrete, and integral abutment bridge girders. Mourad and Tabsh [4] investigated deck slab stresses for integral abutment bridges using two separate bridge models differing in girder cross sections, slab thicknesses, and pile spacings. Lahovich [7] developed live-load distribution factors for an integral abutment bridge, using a "bridge in a backpack" and the folded plate girder bridge in order to quantify the response of each of the bridges under various types of loading. LLDFs have also been quantified for bridges using validated finiteelement models based on measured live-load data such as the study conducted by Hodson et al. [6]. The researchers for this study investigated the live-load behavior of an integral abutment bridge. The integral abutments were found to add considerable restraint to the structure making the AASHTO LRFD live-load distribution factors conservative. Kalayc1 et al. [9] also utilized a validated finite-element bridge model of a concrete deck on steel I-girders in order to determine the LLDFs of two integral abutment bridges in the State of Vermont. While single-span, integral abutment bridges are more commonly constructed, few studies have been performed using finite-element models validated from live-load test data on a single-span, prestressed, integral abutment, and concrete girder bridge to determine LLDFs.

As part of a study to determine the overall behavior of integral abutment bridges, researchers at Utah State University performed live-load testing on a single-span, prestressed concrete girder, and integral abutment bridge near Perry, UT. The setup of this test involved attaching strain gauges and deflectometers at various locations on the bridge. The liveload test consisted of slowly driving trucks across the bridge along predetermined load paths, as well as parking trucks at different locations on the bridge. The data collected from these tests was used to create and validate a finite-element model (FEM) of the bridge. The model was developed using the same dimensions and characteristics as the actual bridge. Boundary conditions, due to the stiffness of the integral abutments, were altered until the FEM and live-load data resulted in a strong correlation. Live-load distribution factors were then obtained using this validated model and compared to those calculated in accordance to procedures recommended in the AASHTO LRFD Bridge Design Specifications [14].

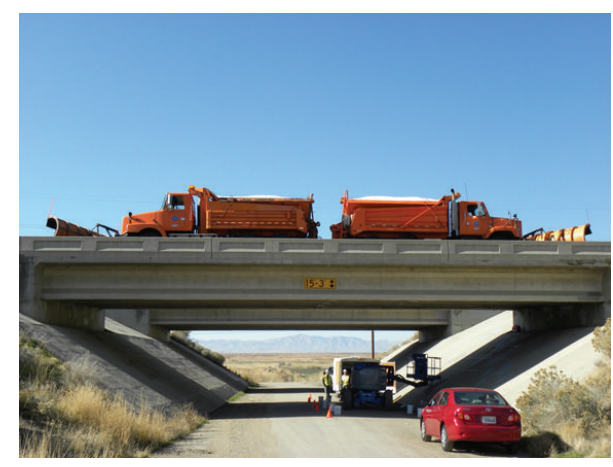

FIgURE 1: Perry Bridge (structure number 1F 205) elevation view during testing.

The AASHTO LRFD and finite-element distribution factors were used to obtain a load rating of the bridge.

Subsequent to the live-load study, a live-load distribution parametric investigation was conducted by incrementally modifying the validated model for changes in span length, deck thickness, edge distance, skew, and fixity. Distribution factors were calculated for each change in individual bridge property and compared with the corresponding calculated distribution factors obtained from the procedures in the AASHTO LRFD Specifications [14]. The results showed that the bridge properties with the largest influence on the liveload distribution were changes in fixity, skew, and edge distance. Changes in these parameters showed that the AASHTO LRFD Specifications were between 10\% nonconservative and $56 \%$ conservative, depending on girder position, loading, and fixity. The parameter with the least amount of influence on live-load distribution was the deck thickness providing a range between 4 and 19\% nonconservative. Depending on which bridge property was modified, both increases and decreases in conservatism were exhibited.

\section{Bridge Description}

The Perry Bridge (structure number 1F 205), as shown in Figure 1, was constructed in 1976. The superstructure was designed as a single-span, prestressed concrete bridge. The bridge is located $80.5 \mathrm{~km}$ (50 miles) north of Salt Lake City, UT. It carries two lanes of northbound traffic, as part of Interstate 15/84 traveling over Cannery Road in the town of Perry, UT. The bridge has a clear span length of $24.4 \mathrm{~m}(80 \mathrm{ft})$ and an overall length of $25.1 \mathrm{~m}(82.5 \mathrm{ft})$. The bridge clearance is $4.68 \mathrm{~m}$ ( $15.3 \mathrm{ft})$. The bridge incurs an average daily traffic (ADT) of approximately 22,000 vehicles, 29 percent of which are trucks. The bridge was designed with no skew but has a superelevation of $2 \%$.

The deck has a width of $13.4 \mathrm{~m}(44.4 \mathrm{ft})$ measured from outside to outside of the barriers. The roadway width is $12.3 \mathrm{~m}(40.5 \mathrm{ft})$ wide measured from the inside of the barriers with a shoulder width of $1.60 \mathrm{~m}(5.25 \mathrm{ft})$ and $3.43 \mathrm{~m}(11.3 \mathrm{ft})$ on the western and eastern sides, respectively. The two traffic lanes are $3.66 \mathrm{~m}(12 \mathrm{ft})$ wide. These dimensions are shown in Figure 2. The deck is comprised of concrete that is 


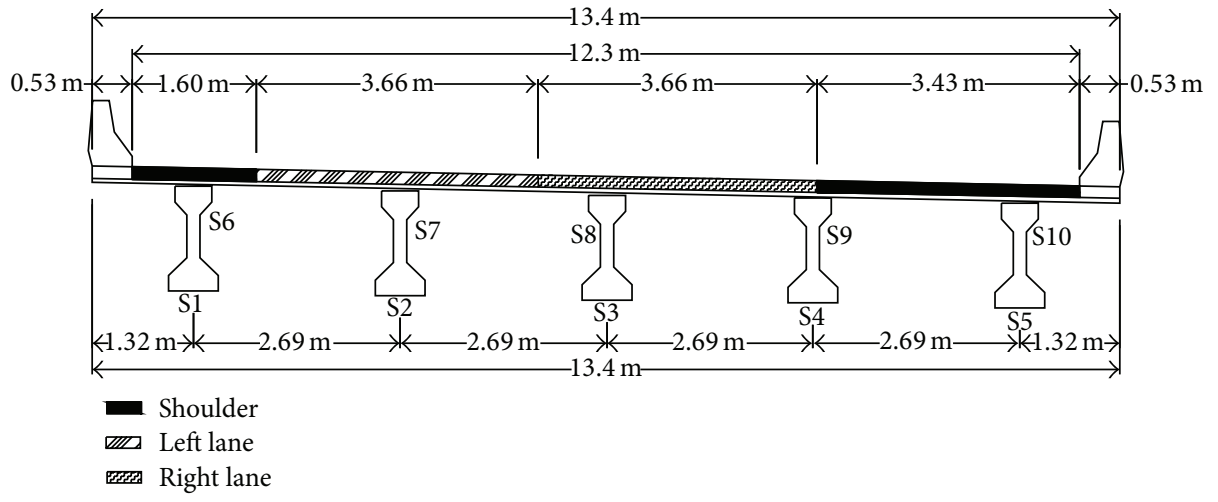

FIgURE 2: Bridge cross-sectional view at Section AA with dimensions and strain gauge placements.

$203 \mathrm{~mm}$ ( 8 in.) thick with an additional 152 to $203 \mathrm{~mm}$ (6 to 8 in.) asphalt overlay. The deck concrete had a specified compressive strength of $24.1 \mathrm{MPa}$ (3500 psi) and was reinforced with number 16 (number 5) bars of Grade 420 (Grade 60) billet-steel. The top reinforcing mat was constructed with $50.8 \mathrm{~mm}$ ( $2 \mathrm{in}$.) of cover. The concrete barriers were $0.85 \mathrm{~m}$ $(2.8 \mathrm{ft})$ tall and were cast with a cold joint along both sides of the bridge. The barriers are reinforced with number 13 (number 4) bars of Grade 420 (Grade 60) steel with a specified cover of at least $38.1 \mathrm{~mm}(1.5 \mathrm{in}$.).

The five precast girders supporting the deck are AASHTO Type IV bridge girders that are $25.1 \mathrm{~m}$ ( $82.5 \mathrm{ft}$ ) long and $1.37 \mathrm{~m}$ $(4.5 \mathrm{ft})$ tall. The girders have a center-to-center spacing of $2.69 \mathrm{~m}(8.8 \mathrm{ft})$. The 56-day specified compressive strength of the girder concrete was $34.5 \mathrm{MPa}(5000 \mathrm{psi})$. The girder was prestressed with sixteen-1.27 cm (0.5 in.) diameter and sevenwired strand that had an ultimate stress of $1860 \mathrm{MPa}(270 \mathrm{ksi})$. The jacking stress was $1400 \mathrm{MPa}(202.5 \mathrm{ksi})$. The shear reinforcement was provided with number 16 (number 5) bars of Grade 420 (Grade 60) steel. The girders were prestressed using a harped strand profile. Both harping points are located $9.75 \mathrm{~m}(32 \mathrm{ft})$ from the girder ends and the centroid of the strands, at the harping point, is $103 \mathrm{~mm}$ (4.06 in.) from the bottom of the girder. At the girder ends, the centroid of the prestressing strands is located at $340 \mathrm{~mm}$ (13.4 in.) from the bottom of the girder. The final prestressing force for each girder, after losses, was calculated to be $3370 \mathrm{kN}$ (757 kips).

The supports of the Perry Bridge superstructure were designed as integral abutments and are $0.76 \mathrm{~m}(2.5 \mathrm{ft})$ thick

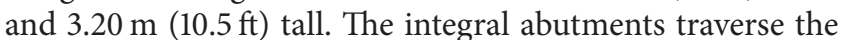
entire width of the bridge. At each abutment, the girder is supported on a $12.7 \mathrm{~mm}$ ( $0.5 \mathrm{in}$.) elastomeric bearing pad. These pads transfer the vertical load from the girders to five concrete drilled piles which each have a maximum allowable design load of $356 \mathrm{kN}$ (80 kips). Wing walls were cast adjacent to both abutment ends and have a total length of $4.72 \mathrm{~m}$ $(15.5 \mathrm{ft})$, a width of $0.30 \mathrm{~m}(1 \mathrm{ft})$, and varied height between $0.61 \mathrm{~m}(2 \mathrm{ft})$ near the abutment and $2.90 \mathrm{~m}(9.5 \mathrm{ft})$ towards the center of the bridge.

At the time of testing, the bridge superstructure was in fairly good condition. The girders did not show any signs of cracking. The wing walls on the east side of the bridge had a vertical crack at the connection of the approach slab and end of the bridge.

\section{Live-Load Test}

The live-load test was conducted by driving a truck or a combination of trucks along predetermined load paths and measuring the corresponding strain, displacement, and temperature using a wireless sensor system that was attached to the bridge superstructure. The sensors were attached at two cross-sectional locations along the bridge. These sensors include ten wireless surface mounted strain sensors and five vertical displacement sensors.

A wireless data acquisition system, from Bridge Diagnostic Inc., was used to record changes in strains during the live-load test. The system utilized four-channel nodes to wirelessly transmit gauge readings along the length of the bridge to a central station by way of a broadband system. The strain gauges were connected utilizing intelliducer sensors that automatically identified the gauge number. All sensor readings were monitored simultaneously during the test at a rate of $40 \mathrm{~Hz}$. The wireless strain sensors (sensors $\mathrm{S} 1$ through S10) were attached at the top of the girder web and on the bottom flange of each girder at $13.1 \mathrm{~m}(43 \mathrm{ft})$ as measured from the south end of the bridge as shown as Cross Section AA in Figure 2. The cross section location for the strain

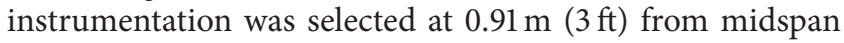
due to the possible influence of the intermediate diaphragm at the midspan.

Displacement transducers were used to measure changes in deflection during testing. The displacement transducers consisted of a base plate that was fixed to the bridge with an attached cantilevered plate. The cantilevered plate had four strain gauges, wired in a full-bridge configuration, attached near the base of the cantilever plate and a wire attached at the tip. The wire extended from the tip of the cantilever plate to a fixed location below the bridge. The wire was then tensioned so that the tip of the cantilevered plate deflected $38 \mathrm{~mm}$ (1.5 in.) downward. The change in strain from the four gauges was used to determine the changes in vertical deflection of the transducer to within $0.025 \mathrm{~mm}$ (0.001 in.). Because the diaphragm would theoretically have no effect 


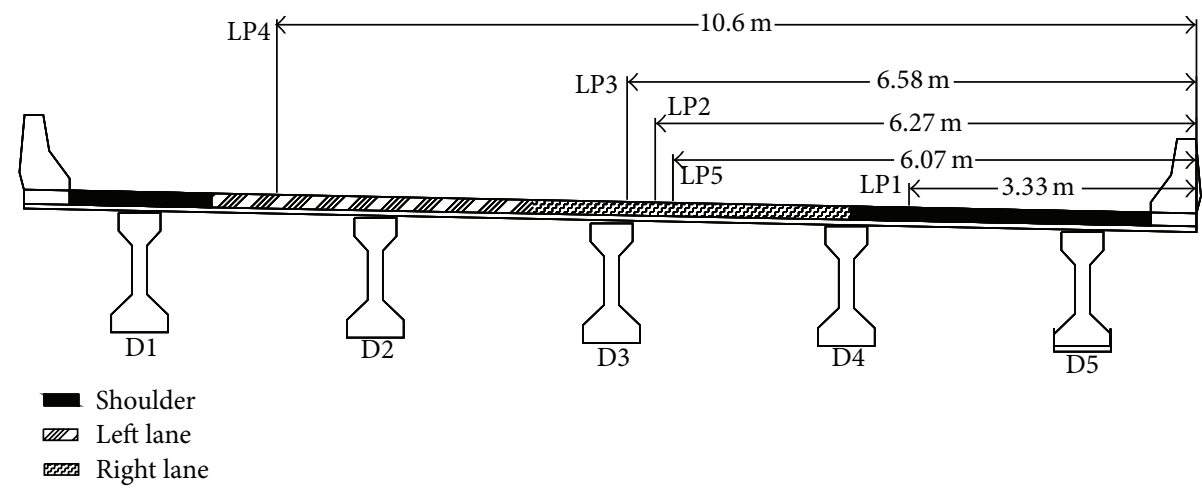

Figure 3: Bridge cross-sectional view at Section BB with deflectometer placements and load paths.

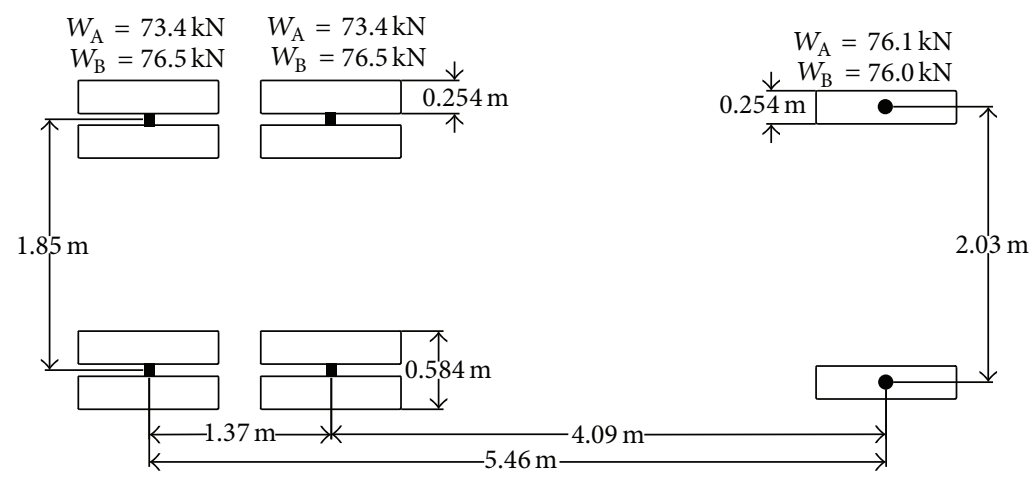

FIgURE 4: Truck A and B weights and dimensions.

on the displacement, the deflection equipment (sensors D1 through D5) was attached on the bottom flange of each of the girders at midspan. The displacement sensors were also monitored wirelessly using the four-channel nodes and the intelliducer. The location of the displacement sensors is provided as Cross Section BB of Figure 3.

Multiple live-load tests were performed using a controlled lane closure by means of a slowdown that provided trafficfree periods on the bridge. This was accomplished by having a highway patrol car slowly drive down the middle of both lanes of the highway, beginning $3.66 \mathrm{~km}$ (2.28 miles) from the bridge. This slowdown allowed for windows of time of four to five minutes of uninterrupted testing. During this time period, the trucks were positioned and the live-load tests on one load path were completed.

Two similar heavily loaded tandem rear axle dump trucks were used to apply the live-load. Truck A had a gross vehicle weight (GVW) of $223 \mathrm{kN}$ (50.1 kips) while Truck B had a GVW of $229 \mathrm{kN}$ (51.5 kips). The distance between the front axle and middle axle was $4.09 \mathrm{~m}(13.4 \mathrm{ft})$ while the distance between the middle axle and back axle was $1.37 \mathrm{~m}(4.49 \mathrm{ft})$. Both trucks had front axle tire spacings of $2.03 \mathrm{~m}(6.66 \mathrm{ft})$ and middle and back axle spacings of $1.85 \mathrm{~m}$ (6.07 ft). Truck A and Truck B had front axle weights of $76.1 \mathrm{kN}$ (17.1 kips) and $76.0 \mathrm{kN}$ (17.1 kips), respectively. Their middle and back axles had weights of $73.4 \mathrm{kN}$ (16.5 kips) and $76.5 \mathrm{kN}$ (17.2 kips), respectively. The researchers had planned on two different trucks but these were the only ones available at the time of testing. A footprint of Trucks A and B is shown in Figure 4.

Five static or pseudostatic (truck driving at $2.24 \mathrm{~m} / \mathrm{s}$ (5 mph)) load cases using different load paths were conducted in all. The drivers tried to maintain the constant velocity throughout the test. Slight variations occurred but nothing that induced dynamic strains. Because different trucks were not available at the time of testing, dynamic testing at higher speeds was not performed. The strains, displacements, and corresponding truck positions were recorded at a frequency of $50 \mathrm{~Hz}$. The lateral truck position of each load path was marked along the entire longitudinal length of the bridge. The lateral position of each load path is provided in Figure 3 measuring from the east side of the bridge to the driver's side front tire. Load Case 1 featured both Trucks A and B statically positioned back-to-back at the midspan of Load Path 1. This load case was intended to maximize the exterior girder response. Load Case 1 was replicated three times. Load Case 2 had two trucks positioned side-by-side. This configuration was intended to maximize the loading on the first interior girder. For this case, Truck A followed Load Path 1 while Truck B followed Load Path 2. Both trucks were driven along their respective load paths at approximately $2.24 \mathrm{~m} / \mathrm{s}$ ( $5 \mathrm{mph})$. This test was replicated twice. Load Case 3 featured both trucks slowly driving along the center of the highway traffic lanes (left and right lanes of Figure 3). Truck A followed Load Path 3 while Truck B followed Load Path 4 . This test was performed 
three times. Load Case 4 had Truck B following Truck A in series psuedostatically along Load Path 1 . This was performed in order to maximize the load on the exterior girder. This test was replicated twice. Load Case 5 was performed twice and featured Truck A psuedostatically driving along Load Path 5.

The longitudinal truck position was monitored during the pseudostatic load cases using an autoclicker which was mounted on the driver side tire of Truck A. The autoclicker, which was also monitored placed an electronic marker in the data file at each wheel revolution. Using the data markers and the known circumference of the tire, the exact location of the truck was determined as it traversed the length of the bridge.

Before using the data collected from the live-load test, an analysis was required to determine whether or not the data was acceptable for use. Two analyses were conducted to ensure accurate data. First, multiple tests were performed for each load case which allowed for a direct comparison between two sets of what should be identical data. In all cases, the measured data between the multiple runs for each load case was within $1 \%$. The second analysis that was conducted on the live-load data was a strain versus deflection analysis for each gauge in order to make sure all of the gauges were reading correctly. This analysis was effective because strain and deflection are proportional. In order to make this comparison, the strain and the deflection were plotted for all five girders for multiple positions. This analysis was completed for multiple load cases and compared to hand calculations when two gauges were dissimilar to identify discrepancies.

Figure 5 shows an influence line for the bottom strain of Girder 2 as the truck was driven along Load Case 5. When the truck was at either end of the bridge, the bottom strain at Section AA for Girder 2 was very small. As the truck was positioned closer to the midspan, the bottom strain increased. A maximum recorded strain for this girder and load case was nearly 11 microstrains. Although the magnitudes varied, these trends were typical for other girders and load cases. Figure 6 shows the deflection measurements for all five girders for Load Case 2. For this particular figure, the data is when the truck was at the midspan of the bridge. Figure 6 shows that Girder 3 experienced the largest deflection. This is due to the lateral position of the truck. The adjacent girders (Girders 2 and 4) experienced a smaller deflection. Girder 5, which was the furthest from the load, experienced the least deflection. These trends were also similar for other load cases.

\section{Finite-Element Analysis}

A finite-element model of the Perry Bridge was created using SAP2000 v.15.0.0 [15]. All structural elements of the bridge model were created using eight-node, solid elements. These elements have three transitional degrees-of-freedom at each node. Various cross-sectional dimensions were used depending on the structural member.

The majority of the deck solids elements were $203 \mathrm{~mm} \times$ $203 \mathrm{~mm} \times 305 \mathrm{~mm}\left(8^{\prime \prime} \times 8^{\prime \prime} \times 12^{\prime \prime}\right)$ rectangles. The dimensions of the solid elements for the girder varied due to the girder shape, but, in all instances, the aspect ratios were kept between 1.5 and 3 . The jersey barrier element dimensions also

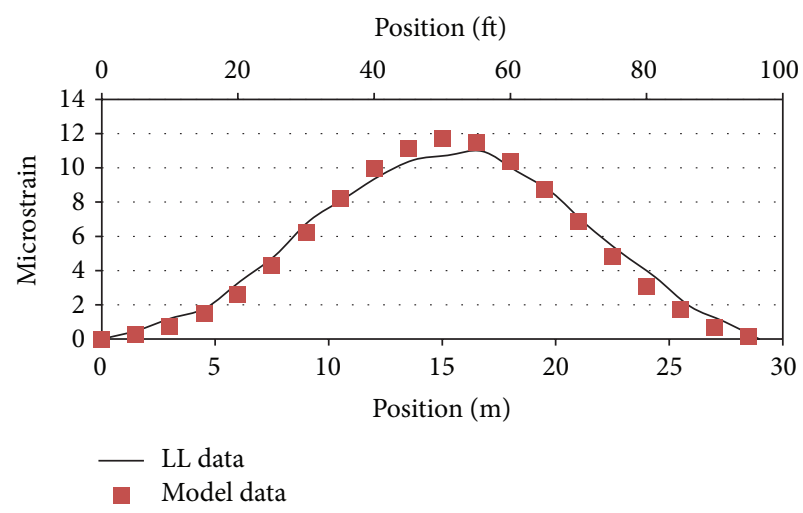

FIGURE 5: Microstrain comparison at midspan between live-load and FEM data for Load Case 5, Girder 2.

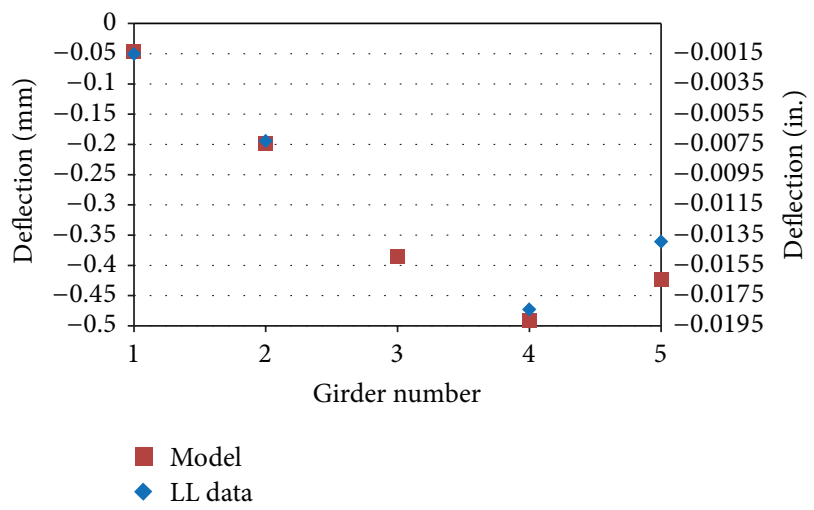

FIGURE 6: Deflection comparison near midspan between live-load and FEM data for Load Case 2, all girders.

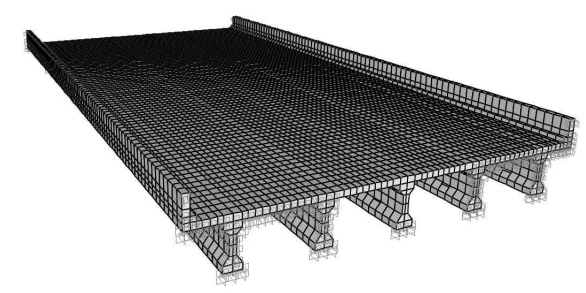

Figure 7: 3D FEM view of the Perry Bridge using solid elements.

varied due to its shape but had aspect ratios between 1.5 and 2. In all, 19,316 joints and 10,752 solids were utilized to develop the FEM. Figure 7 shows a 3D view of the barrier, deck, and girder elements for the Perry Bridge FEM.

In order to validate the accuracy of the finite-element model, the measured strains and deflections from the liveload test were compared to the corresponding calculated strains and deflections of the model. Nodes were created for the FEM in the same respective locations as the strain gauges and deflectometers on the actual bridge. This allowed for a direct comparison with the measured results. The material properties, including the specified concrete compressive 
strength, and therefore the modulus of elasticity for the deck, girder, and barrier elements were initially assigned to the material properties in the FEM based on the specified bridge plans. These properties were increased by approximately $10 \%$ during the validation process to allow for higher in situ values than the specified ones. The properties were kept constant throughout the validation process. Transitional springs were applied at the girder ends of the bridge. The springs were placed at the bottom, along the height of the girder end, and at deck nodes. The magnitude of the springs was systematically increased during the validation process to represent the fixity of the integral abutment of the actual bridge. The final spring stiffness was determined when a trend line with an overall slope as close to 1.0 as possible between the bridge model data and the bridge live-load data was achieved. The final boundary conditions for the bridge were nearly fixed-fixed with transitional springs restraining movement on all but the top $80 \%$ of the middle girder, as well as no transitional restraints on the middle of the deck. This variation in transverse fixity is believed to have been caused by the additional stiffness created by the wing walls on the edge beams. The overall rotational restraint is attributed to the stiffness of the integral abutments.

Figure 5 provides an influence line comparison between the measured live-load and the calculated FEM data of Girder 2 for Load Case 5. The live-load data was monitored continuously while the truck was driven along the bridge. The FEM data was determined discretely with the truck positioned every five feet. As shown, a strong correlation between the bridge model and live-load data was achieved, both in terms of magnitude as well as trend. Figure 6 also provides a comparison between the live-load and FEM data, showing the lateral deflection distribution of the bridge for all five girders for the truck at the midspan of Load Case 2. For this figure, the live-load deflection data for Girder 3 was neglected due to a faulty deflectometer. Based on the results, a strong correlation between the two sets of data was also achieved for the deflection data.

A comparison between the live-load data and FEM microstrains was also performed for other truck positions and load cases. For this comparison, a trend line was calculated and found to have a slope of 1.12 with a coefficient of correlation determined to be over 0.95 suggesting a strong correlation between the two sets of data. Deflection comparisons showed an even stronger correlation with a trend line slope calculated to be 1.06 and a correlation coefficient of 0.99 . These correlations are provided in Figures 8 and 9, respectively.

In order to determine the degree-of-fixity of the Perry Bridge, the sum of all of the girder midspan moments was obtained from the validated FEM and subsequently compared to the midspan girder moments of two single girders of the same bridge length but one with simply supported ends and the other with fixed-fixed supports. For this analysis, the AASHTO HS-20 truck was applied at various longitudinal and transverse positions on the model and the corresponding longitudinal position on the single girders. Based on the comparisons of the results, the approximate percent fixity of the Perry Bridge was determined to be $94 \%$ based on a linear

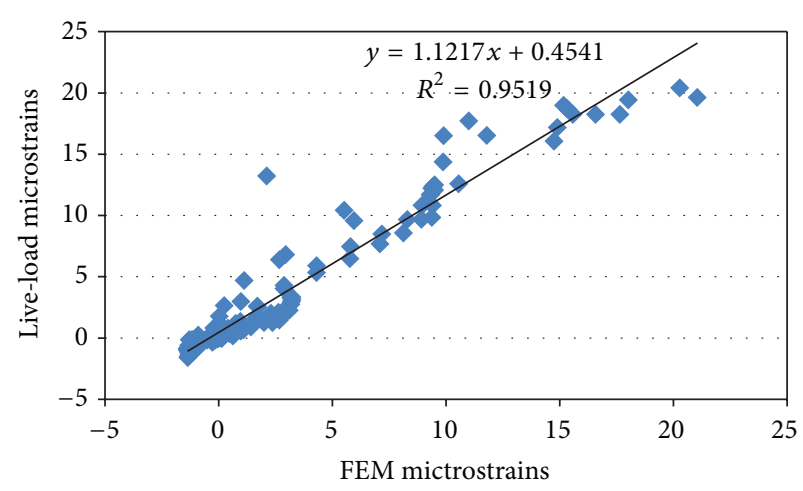

FIGURE 8: Live-load microstrain versus model microstrain near midspan for all girders.

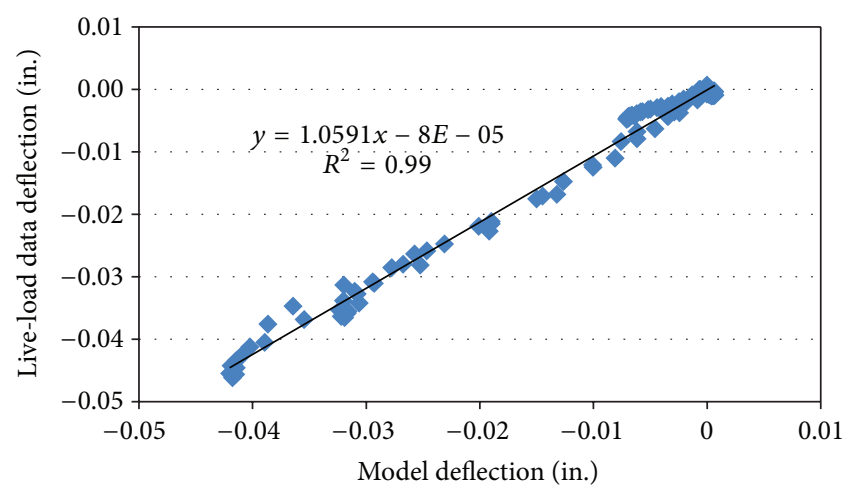

FIgURE 9: Live-load deflection versus model deflection at midspan for all girders.

interpolation. Because of the uncertainty in fixity during the initial design phase, the Perry Bridge was originally designed assuming simply supported end conditions. The actual fixity results in a very conservative midspan moment design and can provide cost savings if taken into account.

\section{Live-Load Distribution Factors}

After the FEM was validated with the live-load data, it was then used to determine live-load distribution factors for the Perry Bridge. The FEM distribution factors were then compared to those calculated using recommended procedures in the AASHTO LRFD Bridge Design Specifications [14]. Distribution factors are used to simplify the design process. The maximum moment caused by a truck (or lane of traffic) is first estimated by treating the bridge as a beam. A designer then obtains the design moments for each girder by multiplying the maximum moment by a factor, which is usually referred to as the live-load distribution factor. The equations provided in the AASHTO Specifications are dependent on the girder location (interior or exterior), skew angle, span length, deck thickness, overhang length, girder spacing, and girder stiffness. However, distribution factors calculated in accordance to the AASHTO Specifications do not take into account possible continuity due to the different types 
TABLE 1: Comparison of distribution factors for single and two loaded lanes cases.

\begin{tabular}{lccccccc}
\hline \multirow{2}{*}{ Number of lanes loaded } & Girder case & AASHTO LRFD (1) & SS FEM (2) & $\begin{array}{c}\text { \% difference } \\
=(1-2) /(1)\end{array}$ & $\begin{array}{c}\text { Fixed FEM } \\
(3)\end{array}$ & $\begin{array}{c}\text { \% difference } \\
=(1-3) /(1)\end{array}$ & $\begin{array}{c}\text { Continuity } \\
=(3-2) /(3)\end{array}$ \\
\hline \multirow{2}{*}{ Single lane } & Interior & 0.54 & 0.12 & $78 \%$ & 0.28 & $47 \%$ & $58 \%$ \\
& Exterior & 0.87 & 0.31 & $64 \%$ & 0.74 & $15 \%$ & $58 \%$ \\
\hline \multirow{2}{*}{ Two lanes } & Interior & 0.76 & 0.19 & $75 \%$ & 0.46 & $39 \%$ & $58 \%$ \\
& Exterior & 0.80 & 0.36 & $55 \%$ & 0.86 & $-8 \%$ & $58 \%$ \\
\hline
\end{tabular}

of abutments available for bridge construction. The current distribution factor equations were developed assuming that the bridge was simply supported.

To obtain more accurate distribution factors using the validated FEM, AASHTO HS20-44 truck loads were applied to the model. This truck has a loading of $35.6 \mathrm{kN}$ ( $8 \mathrm{kips}$ ) on the front axle and $142 \mathrm{kN}$ (32 kips) on the middle and back axles. For calculation of the distribution factors, all axles are separated by a longitudinal distance of $4.27 \mathrm{~m}(14 \mathrm{ft})$. The transverse distance between the wheel spacing for all axles is $1.83 \mathrm{~m}(6 \mathrm{ft})$.

In order to maximize the moment, based on the position of the truck on the bridge in the longitudinal direction, a resultant force analysis was conducted and the location of the middle axle of the truck was determined to be at $0.71 \mathrm{~m}$ $(2.33 \mathrm{ft})$ off the center of the bridge. In order to maximize the interior and exterior girder moments for both single and multiple lane loadings in the transverse direction, all possible lateral truck positions were evaluated by incrementally moving the truck (or trucks for the multiple lane cases) laterally across the width of the bridge. For each lateral load case, all five girder moments were obtained. The maximum FEM single and multiple lane moments were calculated for both the interior and exterior girders. The distribution factor was then obtained by placing a single HS-20 truck on an individual girder at the same longitudinal location as the FEM. This girder was evaluated as both simply supported and fixed. The distribution factors for the bridge could then be calculated for single lane or two lanes loadings, depending on which multipresence factor was applied. The distribution factor could then be determined using

$$
\mathrm{DF}=\frac{M_{\mathrm{FEM}}}{M_{\mathrm{SS} / \mathrm{FF}}} \times \mathrm{MPF},
$$

where $\mathrm{DF}=$ distribution factor $M_{\mathrm{FEM}}=$ maximum FEM girder moment; $M_{\mathrm{SS} / \mathrm{FF}}=$ maximum girder moment of a simply supported or fixed-fixed girder; and MPF = multipresence factor (one lane $=1.2$, two lanes $=1.0$ ).

The AASHTO LRFD Specifications [14] provide equations to calculate the distribution factors for an interior girder with one lane and multiple loaded lanes. In addition, an equation is provided to obtain the exterior girder distribution factor with two or more design lanes loaded. For the exterior girder case with one design lane loaded, the code specifies that the lever rule be used to determine the distribution factor.

Once all of the distribution factors had been calculated in accordance to the AASHTO LRFD Specifications [14] and the FEM, the percent difference was obtained in order to quantify the accuracy of the current code procedures in predicting the load distribution of a concrete girder bridge with integral abutments. In all cases, when the simply supported, single girder $\left(M_{\mathrm{SS}}\right)$ was used, the AASHTO LRFD Specification distribution factors were overly conservative. This is primarily due to the fixity of the actual bridge. The maximum percent difference was $78 \%$ conservative for the single loaded lane case, for an interior girder. However, the governing design case was the exterior girder with two loaded lanes which was 55\% conservative. All girder cases are given in Table 1.

The distribution factor was also calculated based on the fixed boundary condition $\left(M_{\mathrm{FF}}\right)$ of the single girder, resulting in a more realistic end condition and allowing for a more direct comparison of the accuracy of the code distribution factors. The results in Table 1 show that the maximum percent difference between the FEM and fixed-fixed distribution factors was $47 \%$ conservative. However, for the single lane case, the exterior girder controlled the design with the highest distribution factor that was only $15 \%$ conservative. After comparing all the single and multiple loaded lane cases, it was determined that the critical loading condition was for the exterior girder when trucks were applied in two lanes. In this case, the AASHTO LRFD Distribution factor was $8 \%$ unconservative in comparison to the FEM distribution factor.

By comparing the distribution factors for the Perry Bridge with simply supported and fixed-fixed end conditions, the effect of continuity can also be determined. The distribution factor obtained using the simply supported moment contains errors from both the distribution factor calculation and the effect of fixity. Because the Perry Bridge was found to be $94 \%$ fixed, most of the error due to fixity is removed through calculating the distribution factor using fixed-fixed boundary conditions. Therefore, the difference between the two distribution factors would leave the effect of continuity. The results in Table 1 show that the effect of continuity is $58 \%$.

\section{Parametric Study}

In order to quantify the effect that different bridge properties have on the magnitude of the live-load distribution factor, a parametric study was conducted. Bridge properties that are currently influenced in the calculation of the distribution factors in the AASHTO LRFD Bridge Design Specifications [14] are span length, deck thickness, edge distance, and skew. Each bridge property was investigated for this study. In order to evaluate the influence of an individual bridge property, 
various FEMs were created and loaded with the AASHTO HS20-44 truck at the longitudinal position for maximum moment. All possible lateral positions were evaluated in order to maximize the moments in each girder. Except for the parametric study dealing with the effect of fixity, each of the FEMs was simply supported.

For each of the parametric FEMs, the bridge was developed using the same properties as the original Perry Bridge FEM. The bridge property being investigated was then incrementally modified and all other properties were kept constant. Distribution factors were calculated for all girders for each incremental change and then compared to the calculated distribution factors in accordance to the AASHTO LRFD Specifications. By evaluating differences in the magnitude of the distribution factors from the baseline bridge, the general trends were able to provide insight into how changes to the individual bridge properties affected the live-load distribution. For each bridge property parametric study, except for fixity, a distribution factor ratio (FEM/AASHTO distribution factor) was provided and plotted as a function of the corresponding change in the individual bridge property. The ratio of the FEM distribution factor to the AASHTO LRFD distribution factor shows the range in conservatism or unconservatism of the AASHTO empirical relationships. Ratios below one indicate that, for that particular bridge property, the distribution factor calculated according to the AASHTO LRFD Specification is conservative. Conversely, ratios above one show that the distribution factor is nonconservative as compared to the FEM. For all parametric studies, the two lanes loaded, exterior girder had the largest distribution factor and therefore governed the design.

\section{Effects of Span Length}

As the span length increases, longitudinally the bridge becomes more flexible. This reduction in stiffness reduces the load distribution of the cross section. The effect of changes in span length was evaluated at intervals of $9.1 \mathrm{~m}(30 \mathrm{ft})$, beginning at $15.2 \mathrm{~m}(50 \mathrm{ft})$ and ending at $61.0 \mathrm{~m}(200 \mathrm{ft})$. These lengths were chosen to encompass span lengths of typical precast girder bridge lengths allowed by the distribution factor equations in the AASHTO LRFD Specifications [14]. After obtaining the controlling distribution factors, the percent differences between the FEM and AASHTO LRFD Specifications were found to be between $25 \%$ nonconservative and $8 \%$ conservative depending on the span length. At a span length of $15.2 \mathrm{~m}$ ( $50 \mathrm{ft}$ ), the FEM distribution factor was $8 \%$ conservative but as the span length is increased, the AASHTO LRFD Specifications became nonconservative and the nonconservatism increased with increasing span length. Figure 10 provides the distribution factor ratio for various span lengths for the exterior girder with two lanes loaded. This region of nonconservatism has been observed by other researchers, that is, $[5,6]$.

The solitary case where with an increase in span length the AASHTO LRFD Specifications become more conservative is for the single lane loaded, exterior girder. This is primarily due to this case being calculated using the lever rule which is

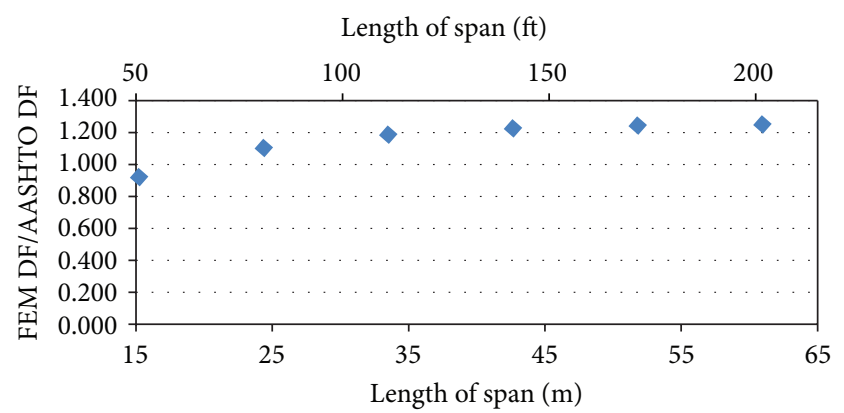

FIGURE 10: FEM distribution factor/AASHTO Distribution Factor versus length of span for the case with exterior girder, two lanes loaded.

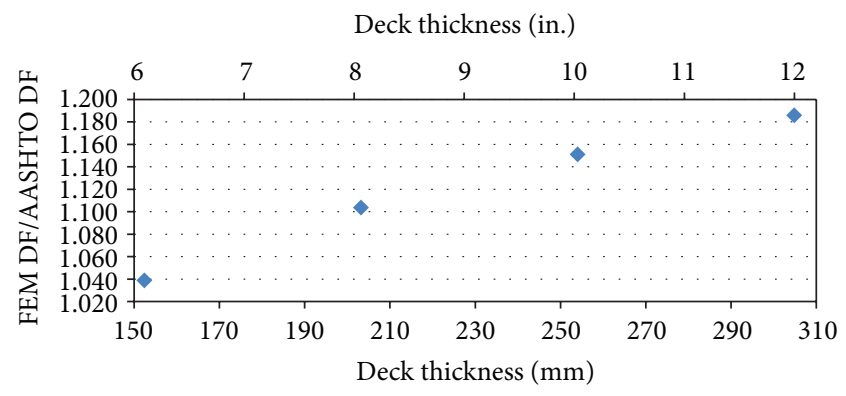

FIGURE 11: FEM distribution factor/AASHTO Distribution Factor versus deck thickness for the case with exterior girder, two lanes loaded.

not a function of span length but only of edge distance, skew, and spacing.

\section{Effects of Deck Thickness}

The effect of deck thickness was evaluated by calculating the distribution factors for deck thicknesses of $0.15 \mathrm{~m}$ (6 in.), $0.20 \mathrm{~m}$ (8 in.), $0.25 \mathrm{~m}$ (10 in.), and $0.30 \mathrm{~m}$ (12 in.). Increasing the deck thickness increases the transverse bending stiffness. This leads to an increase in the ratio of transverse-to-longitudinal stiffness, which, in turn, implies a more uniform distribution of girder moments and a lower live-load distribution factor. After obtaining the distribution factors for the various load cases, the controlling distribution factor was obtained from the exterior, two lanes loaded case. Based on these results, the AASHTO LRFD Specifications were determined to be between $4 \%$ and $19 \%$ nonconservative. As the deck thickness increases, the AASHTO LRFD Specifications become more and more nonconservative, as shown in Figure 11. This implies that the relationships in the AASHTO LRFD Specification overpredict the influence that increases in slab thickness has on the live-load distribution. Similar to the study for increases in span length, all cases become more nonconservative, except for the exterior girder single lane loaded case. This is due to the lack of the lever rule taking into account the deck thickness. 


\section{Effects of Skew}

Changes in skew were evaluated every 15 degrees from 0 to 60 degrees. After obtaining the distribution factors for all girders for a particular skew angle, the controlling girder was determined. The AASHTO LRFD Specifications were found to be between $10 \%$ nonconservative and $56 \%$ conservative for the two lanes loaded, exterior girder. As the skew angle increases, the AASHTO LRFD Specifications become more conservative. This trend occurs for all load cases because skew affects the lever rule, the AASHTO LRFD Specification equations, and the FEM.

\section{Effects of Edge Distance}

The effect of edge distance was evaluated for distances of $0.46 \mathrm{~m}(1.5 \mathrm{ft}), 0.76 \mathrm{~m}(2.5 \mathrm{ft}), 1.1 \mathrm{~m}(3.5 \mathrm{ft}), 1.4 \mathrm{~m}(4.5 \mathrm{ft})$, and $1.7 \mathrm{~m}(5.5 \mathrm{ft})$. This range was chosen to include most of the values allowed in the AASHTO LRFD Specifications. After evaluating all of the load cases, the AASHTO distribution factor for the exterior girder, two lanes loaded case was determined to be between $24 \%$ nonconservative and $17 \%$ conservative. For the initial condition of $0.46 \mathrm{~m}(1.5 \mathrm{ft})$, the AASHTO LRFD Specifications are nonconservative but as the edge distance increases, the AASHTO LRFD Specifications became conservative at an edge distance of $1.07 \mathrm{~m}(3.5 \mathrm{ft})$, as shown in Figure 12. This is also the case for the single loaded exterior girder. The single and multiple loaded interior girder cases are approximately constant for any change in edge distance.

\section{Load Rating}

Two separate types of load ratings are determined in order to define the load capacity of a bridge, the inventory rating and the operating rating. The inventory rating, when multiplied by the controlling bending moment caused by a HS20-44 truck, specifies the maximum live-load that the bridge can safely sustain for an undetermined length of time. The operating rating, when multiplied by the same moment, specifies the largest live-load that the bridge is allowed to sustain under the AASHTO LRFD Specification [14]. The load ratings are determined by

$$
\mathrm{RF}=\frac{R_{n}-\gamma_{D} D}{\gamma_{L} L(1+I)},
$$

$\mathrm{RF}=$ bridge load rating (operating or inventory), $R_{n}=$ nominal flexure capacity, $\gamma_{D}=$ dead load factor $(1.3), \gamma_{L}=$ liveload factor (1.3 for operating, 2.17 for inventory), $D=$ nominal dead load effect (composite and non-composite dead load), $L=$ nominal live-load effect (caused by HS20-44 truck), and $I=$ live-load impact factor $(15.24 /(L+38))$.

The operating and inventory load ratings were calculated for the Perry Bridge based on the controlling distribution factors from the AASHTO LRFD Specifications, the simply supported FEM, and the fixed-fixed FEM. These ratings are provided in Table 2. The AASHTO LRFD Specification controlling distribution factor was 0.87 based on the single lane loaded, exterior girder case. The controlling distribution

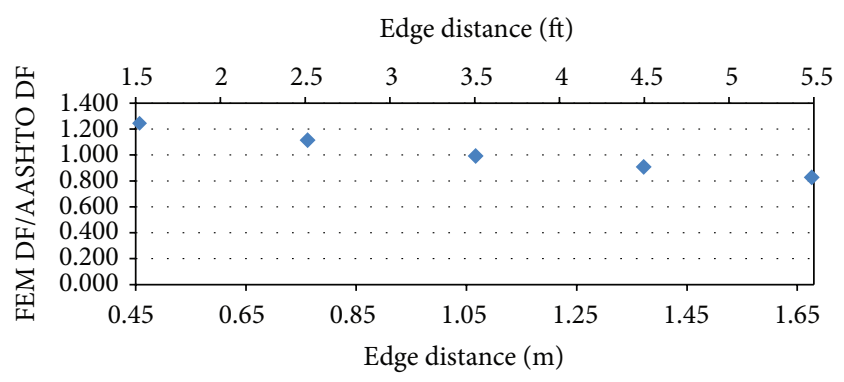

FIGURE 12: FEM distribution factor/AASHTO Distribution Factor versus edge distance for the case with exterior girder, two lanes loaded.

TABLE 2: Load ratings using the AASHTO and FEM results.

\begin{tabular}{lcccc}
\hline & \multirow{2}{*}{ Fixity } & Distribution factor & \multicolumn{2}{c}{ Load ratings } \\
& & & Inventory & Operating \\
\hline AASHTO & SS & 0.87 & 0.47 & 0.78 \\
AASHTO & FF & 0.87 & 2.19 & 3.65 \\
FEM & FF & 0.74 & 2.57 & 4.29 \\
\hline
\end{tabular}

factor for the simply supported FEM and fixed-fixed FEM were 0.36 and 0.86 , respectively. Both the controlling distribution factors for the FEMs were the two lanes loaded, exterior girder case. As shown, according to the AASHTO LRFD Specifications and simply supported FEM, this bridge should not be capable of bearing the load of the HS20-44 because their load ratings fall below one. The load ratings provided by the fixed-fixed FEM, however, would allow this type of loading which shows that fixity needs to be taken into account. In addition, the analysis shows that the AASHTO LRFD Specifications ratings are more than twice as conservative as the simply supported FEM ratings. Hodson et al. [6] also found that the AASHTO LRFD Specifications were overly conservative in determining load ratings of bridges.

\section{Summary and Conclusions}

As part of an investigation into the behavior of integral abutment bridges, a live-load test was conducted on a bridge in Perry, UT. A finite-element model (FEM) was created with the same bridge parameters and validated with the live-load test data. The bridge distribution factors determined from validated FEM were then compared to calculated distribution factors using equations recommended in the AASHTO LRFD Bridge Design Specifications. Parametric studies on the influence of changes in span length, deck thickness, edge distance, skew, and fixity on live-load distribution were also conducted. The results of the research lead to the following conclusions.

(i) Due to the integral abutment support system, the Perry Bridge does not act as a simply supported bridge but instead was determined to be $94 \%$ fixed. In order to provide more adequately sized and economical bridges, the AASHTO LRFD Specification equations need to be adjusted to take into account the fixity of a bridge. 
(ii) The live-load test data led to a subsequent finiteelement model derived of solid elements with aspect ratios no greater than 3 . A trend line and correlation coefficient were used to determine the extent to which the two sets of data were correlated. The trend line for the strain comparison had a slope of 1.12 with a coefficient of correlation determined to be over 0.95. The deflection comparison had an even stronger correlation with a trend line slope of 1.06 and a correlation coefficient of 0.99 .

(iii) The comparison between the FEM distribution factor from the live-load test and the AASHTO LRFD Specifications distribution factor was taken for both a simply supported FEM and a fixed-fixed FEM. For each, the controlling case was the two lanes loaded, exterior girder. The simply supported FEM as compared to the AASHTO LRFD Specification had a percent difference of $55 \%$ on the conservative side. The fixed-fixed FEM as compared to the AASHTO LRFD Specification had a percent difference of $8 \%$ on the nonconservative side. This indicates that the bridge falls somewhere in between the simply supported and fixed-fixed cases.

(iv) The effect of continuity of the bridge was determined to be $58 \%$ through determining the percent difference for the distribution factors obtained with simply supported boundary conditions and fixed-fixed boundary conditions. Because the Perry Bridge is nearly fixed-fixed, and both distribution factors show the error in the distribution factor calculation; the difference between the two distribution factors shows the effect of continuity.

(v) The results of the parametric study indicated that the bridge properties with the largest influence on bridge live-load distribution were fixity, skew, and changes in edge distance. The change in fixity caused the LLDFs to vary from 0.88 for a simply supported bridge to 0.35 for a fixed-fixed bridge. The skew and changes in edge distance showed the AASHTO LRFD Specifications to be between $10 \%$ nonconservative and $56 \%$ conservative and between $24 \%$ nonconservative and $17 \%$ conservative, respectively.

(vi) The results of the parametric study also indicated that the bridge properties with the smallest influence were deck thickness and span length. The AASHTO LRFD Specifications were determined to be between $4 \%$ and $19 \%$ conservative for the deck thickness and between $25 \%$ nonconservative and $8 \%$ conservative for the span length.

(vii) Load ratings were determined for the fixed-fixed FEM and the AASHTO LRFD Specifications based upon using both simply supported and fixed-fixed moments. For the AASHTO LRFD Specifications using simply supported moments as in regular design standards, the inventory and operating load ratings were determined to be 0.47 and 0.78 , respectively. When using the fixed-fixed moments for the AASHTO LRFD Specifications, the inventory and operating load ratings increased to 2.19 and 3.65, respectively. For the fixed-fixed FEM, the inventory and operating load ratings were determined to be 2.57 and 4.29, respectively. This shows that if a bridge lacks a sufficient load rating, determining the fixity of the bridge has a large effect in increasing the load rating. In addition, a model study provides an even more accurate and larger load rating that would prevent a bridge from being labeled as structurally deficient.

\section{Conflict of Interests}

The authors declare that there is no conflict of interests regarding the publication of this paper.

\section{Acknowledgments}

This publication was supported by a subcontract from Rutgers University, Center for Advanced Infrastructure and Transportation (CAIT), under DTFH61-08-C-00005 from the U.S. Department of Transportation Federal Highway Administration (USDOT-FHWA). Any opinions, findings, and conclusions or recommendations expressed in this publication are those of the authors and do not necessarily reflect the views of Rutgers University or those of the U.S. Department of Transportation Federal Highway Administration.

\section{References}

[1] M. Burke, "Integral bridges," in Integral and Semi-Integral Bridges, pp. 1-19, Wiley-Blackwell, Chichester, UK, 2009.

[2] A. Paraschos and A. M. Made, "Integral Abutment Bridges-a survey on the status of use, problems and costs associated with integral abutment bridges, Better Roads, pp. 1-9, February 2011.

[3] D. V. Jáuregui and P. J. Barr, "Nondestructive evaluation of the I-40 bridge over the Rio Grande River," Journal of Performance of Constructed Facilities, vol. 18, no. 4, pp. 195-204, 2004.

[4] S. Mourad and S. W. Tabsh, "Deck slab stresses in integral abutment bridges," Journal of Bridge Engineering, vol. 4, no. 2, pp. 125-130, 1999.

[5] M. Dicleli and S. Erhan, "Live load distribution formulas for single-span prestressed concrete integral abutment bridge girders," Journal of Bridge Engineering, vol. 14, no. 6, pp. 472-486, 2009.

[6] D. J. Hodson, P. J. Barr, and M. W. Halling, "Live-load analysis of posttensioned box-girder bridges," Journal of Bridge Engineering, vol. 17, no. 4, pp. 644-651, 2012.

[7] A. Lahovich, New technologies in short span bridges: a study of three innovative systems [M.S. thesis], University of Massachusetts Amherst, Amherst, Mass, USA, 2012.

[8] H. Cai, O. Abudayyeh, I. Abdel-Qader, U. Attanayake, J. Barbera, and E. Almaita, "Bridge deck load testing using sensors and optical survey equipment," Advances in Civil Engineering, vol. 2012, Article ID 493983, 11 pages, 2012.

[9] E. Kalayc1, S. A. Civjan, S. F. Breña, and C. A. Allen, "Load testing and modeling of two integral abutment bridges in Vermont, US," Structural Engineering International, vol. 21, no. 2, pp. 181188, 2011. 
[10] E.-K. Kim, H. Oh, and J. Sim, "Semiempirical methodology for estimating the service life of concrete deck panels strengthened with fiber-reinforced polymer," Mathematical Problems in Engineering, vol. 2014, Article ID 273693, 13 pages, 2014.

[11] T. Ebeido and J. B. Kennedy, "Shear distribution in simply supported skew composite bridges," Canadian journal of civil engineering, vol. 22, no. 6, pp. 1143-1154, 1995.

[12] D. Ryan and R. Hindi, "Live load distribution factors for castin-place concrete box girder bridges," in Proceedings of the Structures Congress: Crossing Borders, April 2008.

[13] S.-T. Song, Y. H. Chai, and S. E. Hida, "Live-load distribution factors for concrete box-girder bridges," Journal of Bridge Engineering, vol. 8, no. 5, pp. 273-280, 2003.

[14] AASHTO, AASHTO LRFD Bridge Design Specifications, American Association of State Highway and Transportation Officials, Washington, DC, USA, 5th edition, 2010.

[15] Computers and Structures Inc, SAP2000, v. 15.0.0, Berkeley, Calif, USA, 2011 

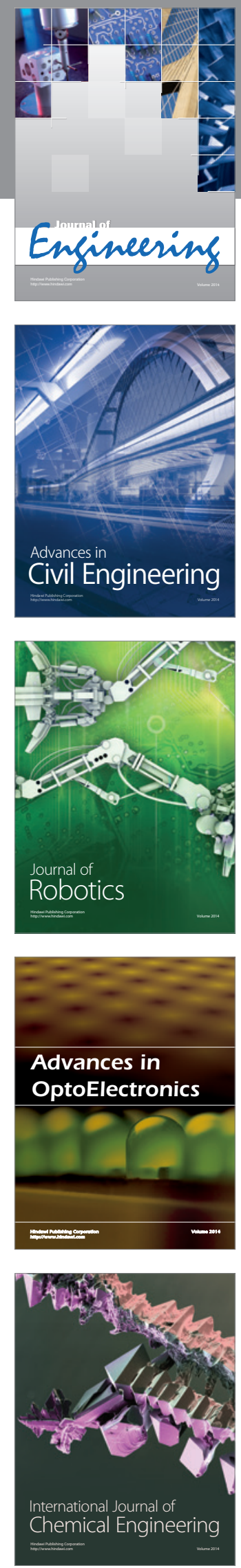

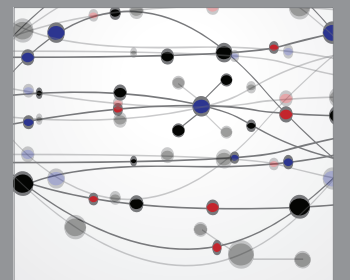

The Scientific World Journal
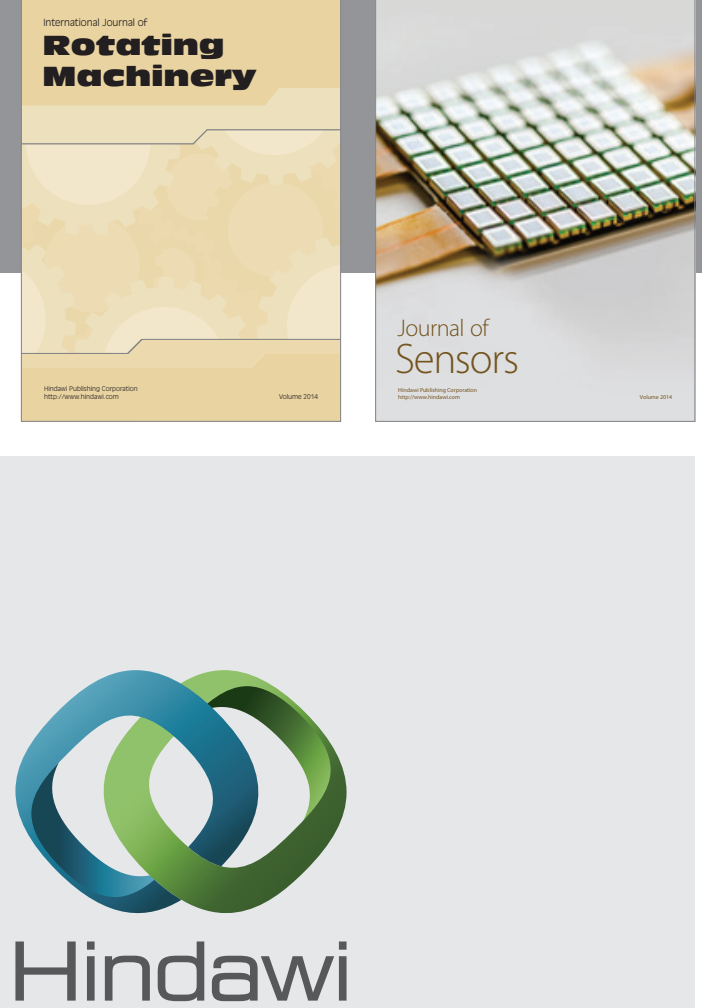

Submit your manuscripts at http://www.hindawi.com
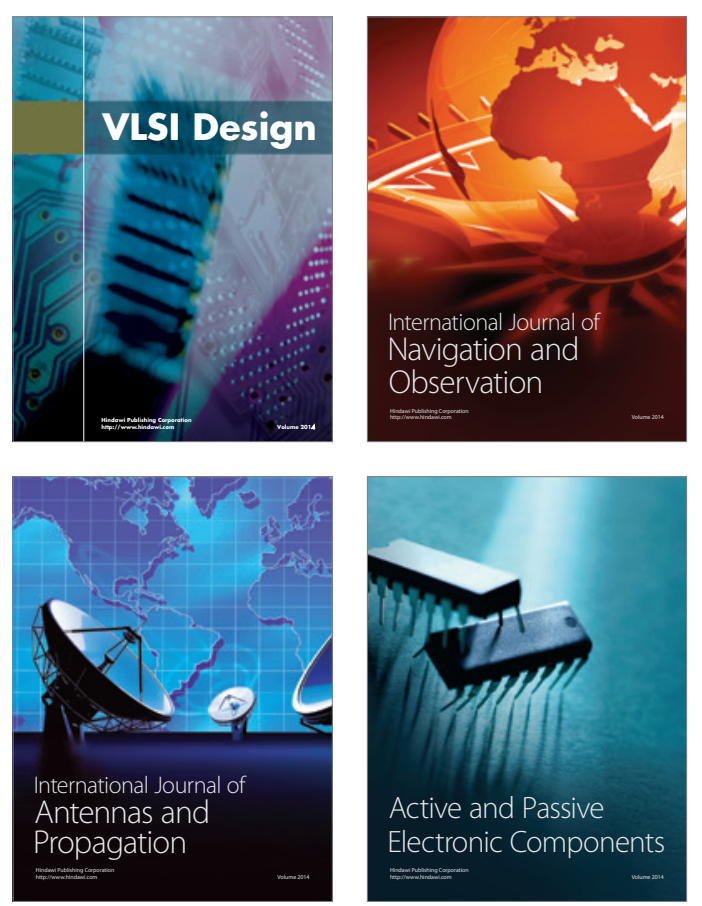
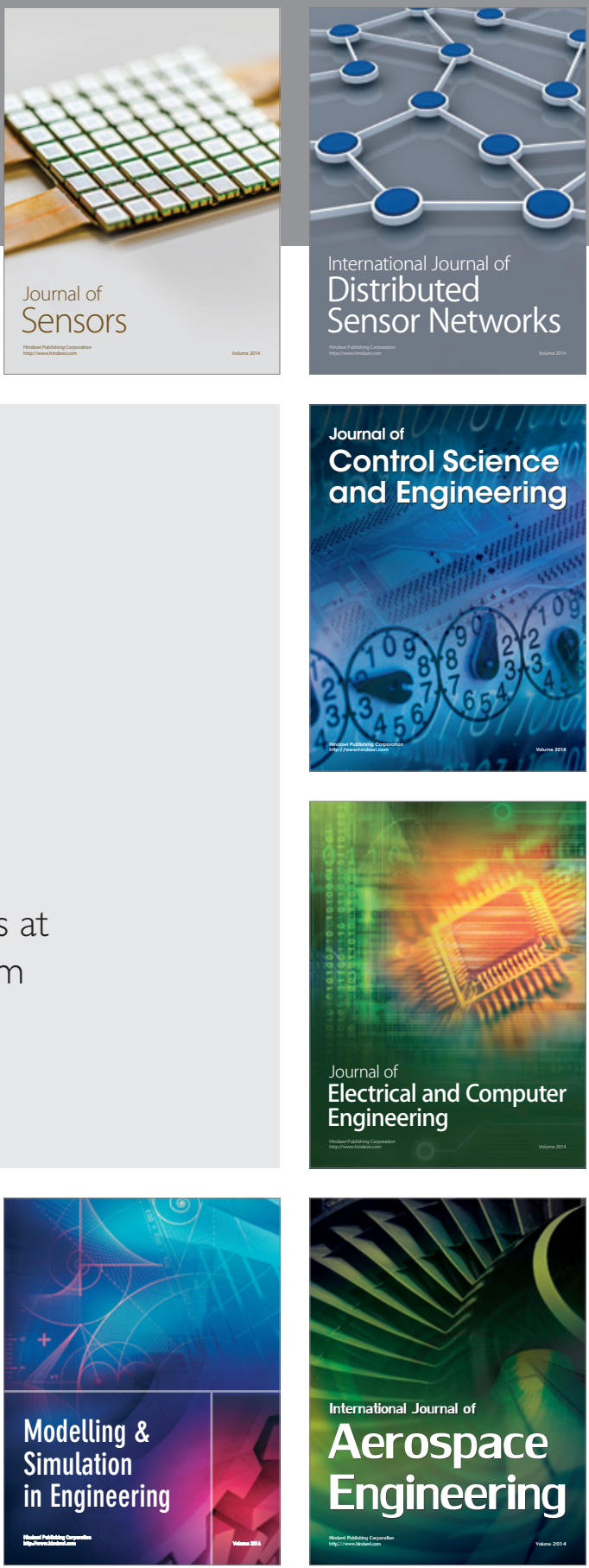

Journal of

Control Science

and Engineering
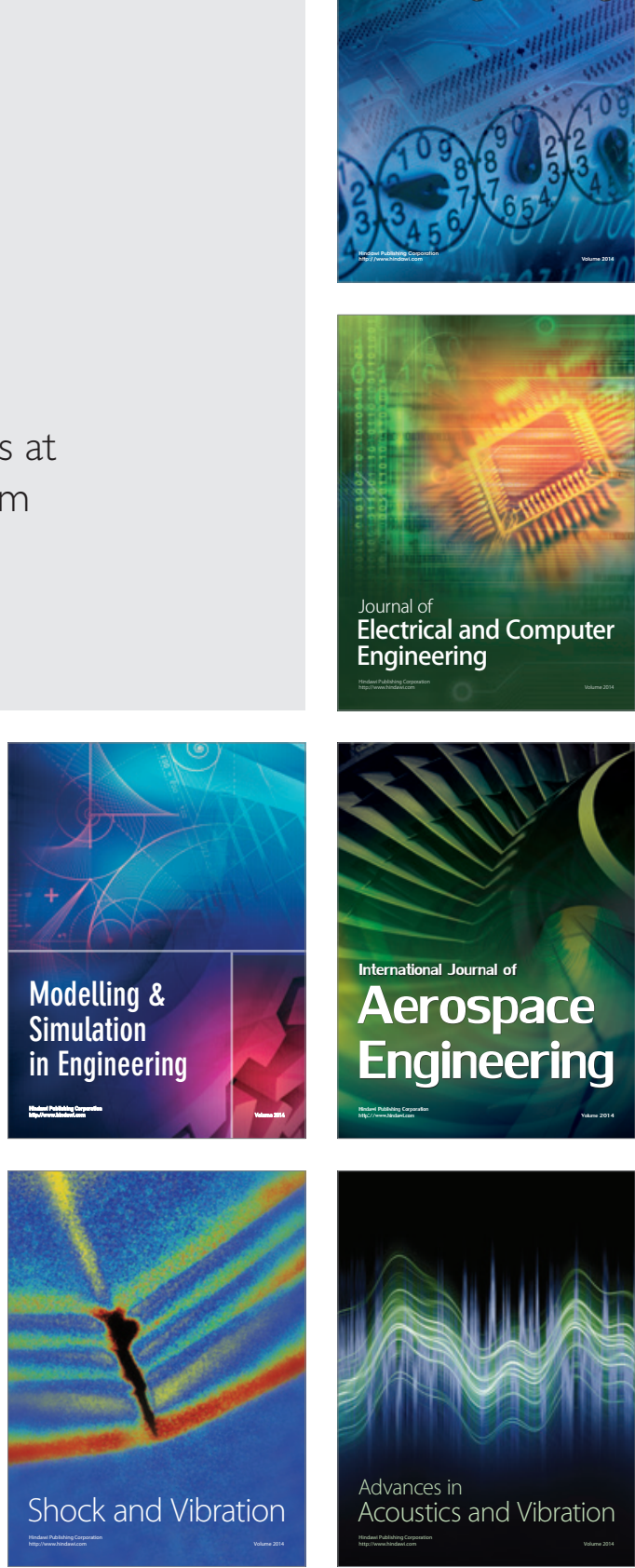